\title{
Mutation and Characterization of an Albino Mutant of Monascus sp. Isolated from the Cikapundung River, Bandung
}

\author{
TIANA MILANDA**, MARLIA SINGGIH WIBOWO, \\ TUTUS GUSDINAR, AND HARYANTO DHANUTIRTO
}

School of Pharmacy, Institut Teknologi Bandung, Jalan Ganesha 10, Bandung 40132, Indonesia

\begin{abstract}
Monascus sp. isolated from Cikapundung River, Bandung was mutated using ethyl methanesulfonate $(2.5 \%$, 90 min). Previously, this wild type was identified as Monascus purpureus ITBCC-HD-F001 employing random amplification polymorphic DNA (RAPD). Stability of the mutant was observed using color consistency and mutant stability (sub-culturing for five generations) tests. Genetic variation of the mutant (M. purpureus ITBCC-HDF002) was confirmed by RAPD. One of the DNA bands of 1150 bp was found in the albino mutant but not in the wild type, so it was considered as a genetic variation resulting from the mutation process. The albino mutant was characterized by comparing the growth curve, biomass production curve, and the monascidin A production curve of both strains i.e. wild type and the albino mutant. Monascidin A production of the mutant was higher than that of the wild type.
\end{abstract}

Key words: Monascus sp., ethyl methanesulfonate, random amplification polymorphic DNA, albino mutant, monascidin

Monascus purpureus is a rice fermentation fungus used to produce 'angkak'. This fermentation product has been used for a long time as a food colorant, a meat preservative, and a traditional medicine, especially by the people of South China, Japan, and South East Asia. Various secondary metabolites have been isolated from 'angkak', such as pigments, an antihypercholesterolemic agent (monacolin K), and an antibacterial substance (monascidin A) (Blanc et al. 1998a; Lakrod et al. 2000). Blanc et al. (1995) reported that monascidin A was citrinin, a mycotoxin that has carcinogenic, teratogenic, and nephrotoxic properties. The presence of monascidin A in products fermented by Monascus raises concerns about the safety of the products.

To obtain fermented products free from monascidin A, Blanc et al. (1998b) tested three procedures. Firstly, they conducted a selection among Monascus strains to find one that did not produce monascidin A, secondly, they modified fermentation conditions, and thirdly, they degraded monascidin A found in fermentation products. These methods could suppress or eliminate monascidin A, but unfortunately the process also decreased the production of pigments and monacolin K significantly. This could happen because these three secondary metabolites were all synthesized via the polyketide biosynthesis pathway catalyzed by polyketide synthase (PKS). Characterization of enzymatic reactions at the branch point of the three-metabolite biosynthesis pathways is needed to properly develop a strategy to produce pigments and monacolin $\mathrm{K}$ free from monascidin $\mathrm{A}$. (Hajjaj et al. 1999).

To characterize those enzymatic reactions, a study of PKS enzymes and genes at the molecular level is needed. This kind of study requires a transformation system for $M$. purpureus that uses an albino mutant deficient in monacolin $\mathrm{K}$ or citrinin (monascidin A) synthesis as recipients. The use

${ }^{*}$ Corresponding author and ₹Present address, Faculty of Pharmacy, Universitas Padjadjaran, Jalan Raya Bandung-Sumedang Km 21, Jatinangor 45363, Indonesia; Phone/Fax: +62-22-7796200,

E-mail: tiana_milanda@yahoo.com of albino mutant has a higher priority because clone selection for the recipient of pigment biosynthesis gene can be conducted from the colonies that are able to reverse the non-pigment producing capability. (Blanc et al. 1998b). This albino mutant is still not available, especially one that is obtained from local Indonesian isolates.

In this research, we carried out the mutation of Monascus sp. from local isolates and characterized a resultants albino mutant. These are the initial steps to develop an efficient transformation system for M. purpureus.

\section{MATERIALS AND METHODS}

Monascus sp. Strains. As the parental strain we used Monascus sp. isolated from the Cikapundung River, Bandung. Two other fungal strains were used as standards, i.e. Monascus purpureus CECT2955T (Universidad de Valencia, Spanyol) and Monascus ruber DSM1561 (Biotechnology Research Center, LIPI, Cibinong). These three fungal strains were grown on yeast extract-malt extract-peptone (YMP) agar $(0.3 \%[\mathrm{w} / \mathrm{v}]$ yeast extract, $0.3 \%[\mathrm{w} / \mathrm{v}]$ malt extract, $0.6 \%[\mathrm{w} / \mathrm{v}]$ peptone, $2 \%[\mathrm{w} / \mathrm{v}]$ glucose, $2 \%[\mathrm{w} / \mathrm{v}]$ agar) for $7-10$ days at $28{ }^{\circ} \mathrm{C}$. The spore suspension was obtained from Monascus sp. solid culture on YMP agar, and then the spore concentration was adjusted to: $\%$ transmittance $(\mathrm{T})=25 \%$ at wavelength $(\lambda)=660 \mathrm{~nm}$ which was equal to $2.25 \times 10^{4}$ spores $\mathrm{ml}^{-1}$.

Identification of Monascus sp. Employing RAPD. Identification of Monascus sp. was carried out employing RAPD according to the procedure by Campoy et al. (2003), and replicated three times. Five milliliters aliquots of each strain Monascus sp., M. purpureus CECT 2955T and M. ruber DSM1561 was inoculated into $45 \mathrm{ml}$ YMP broth medium, and then shaken at $150 \mathrm{rpm}$ at $28^{\circ} \mathrm{C}$ for $18 \mathrm{~h}$. Fungal mycelium was harvested by centrifugation at $107,141 \mathrm{x} \mathrm{g}$ at room temperature for three min. After that, fungal DNA was isolated using a Wizard Genomic DNA Purification Kit (Promega). From each strain, 200 ng of DNA was amplified in 
a solution containing 0.5 unit Taq DNA polymerase (Promega), 90 nmoles magnesium chloride (Promega), 8 pmoles primer CRL9 (5'-CAGCCGCCCC-3') or CRL12 (5'-CGCCGCCCG-3') (Proligo-Sigma), 5 nmoles dNTP (Promega) in a 2700 thermocycler (Applied-Bioscience). The PCR program consisted of initial denaturation $\left(4 \mathrm{~min}, 94^{\circ} \mathrm{C}\right)$, followed by 44 cycles each of which consisted of denaturation (40 sec, $\left.94^{\circ} \mathrm{C}\right)$, hybridization $\left(60 \mathrm{sec}, 34^{\circ} \mathrm{C}\right)$, and elongation $(120 \mathrm{sec}$, $72^{\circ} \mathrm{C}$ ), and then terminated by final elongation for $10 \mathrm{~min}$ at $72{ }^{\circ} \mathrm{C}$. Electrophoresis was conducted on $1 \%(\mathrm{w} / \mathrm{v})$ agarose gel using IX TAE buffer at 70-80 volt for $90 \mathrm{~min}$.

Mutation of Parental Strain M. purpureus. Parental strain M. purpureus ITBCC-HD-F001 was mutated using ethyl methanesulfonate (EMS) according to the procedure of Susilowati (1997). A $5 \mathrm{ml}$ aliquot of parental strain suspension was inoculated into $45 \mathrm{ml}$ YMP broth medium, and then shaken at $150 \mathrm{rpm}$ at $28{ }^{\circ} \mathrm{C}$ for $64 \mathrm{~h}$. Ten milliliters of this liquid culture was then centrifuged at $5357 \times \mathrm{g}$ at $4{ }^{\circ} \mathrm{C}$ for $10 \mathrm{~min}$, and then the mycelium sediment was suspended in $10 \mathrm{ml}$ of $200 \mathrm{mM}$ phosphate buffer $\mathrm{pH}$ 7.0. Portions of $1.0 \mathrm{ml}$ mycelium suspension and $100 \mu \mathrm{l}$ of $2 \%$ (w/v) glucose were placed in $25 \mathrm{ml}$-Erlenmeyer flasks, and then sufficient quantity of EMS and $200 \mathrm{mM}$ phosphate buffer $\mathrm{pH} 7.0$ were added each flask to obtain a variation of EMS concentrations of $0,1,2,3,4 \%(\mathrm{v} / \mathrm{v})$. All flasks were shaken at $150 \mathrm{rpm}$ at 28 ${ }^{\circ} \mathrm{C}$ for 45 and $60 \mathrm{~min}$. After that, $2 \mathrm{ml}$ of $5 \%$ sodium thiosulfate was added. After shaking at $150 \mathrm{rpm}$ at $28^{\circ} \mathrm{C}$ for $20 \mathrm{~min}$, the fungal suspension was centrifuged at $5357 \mathrm{x}$ g at $4{ }^{\circ} \mathrm{C}$ for $10 \mathrm{~min}$. The sediment was resuspended in $1 \mathrm{ml}$ of $200 \mathrm{M}$ phosphate buffer $\mathrm{pH} 7.0$ and this suspension was then gradually diluted. A $100 \mu \mathrm{l}$ aliquot of each dilution was inoculated on YMP agar and incubated for $4-7$ days at $28^{\circ} \mathrm{C}$. The number of colonies (both red and white) was observed, the percentage of mutant viability and mutation efficiency were determined, and then the death curve was constructed. The mutation process was repeated with EMS concentrations of $0,1.0,1.5,2.0,2.5,3.0 \%(\mathrm{v} / \mathrm{v})$ with 90 min incubation periods.

White colonies from the mutation process were grown again on YMP-G agar (YMP agar with $8 \%$ [w/v] glucose) for seven days at $28{ }^{\circ} \mathrm{C}$ for the color consistency test. The colonies that remained white in color were sub-cultured for five generations on YMP agar for mutant stability testing.

Genetic Variations of M. purpureus Albino Mutant. Genetic variation of $M$. purpureus albino mutant was detected employing RAPD with three replications using the same procedure previously used in the identification of the parental strain. M. purpureus parental strain was used as the standard.

The Growth of M. purpureus Parental Strain and Its Albino Mutant. Five milliliters suspensions of parental strain and albino mutant was each inoculated into $45 \mathrm{ml}$ YMP broth, and then shaken at $150 \mathrm{rpm}$ at $28^{\circ} \mathrm{C}$. Culture samples from both strains were taken every six hours until the stationary growth phase was reached. All culture samples were centrifuged at $3571 \mathrm{xg}$ for $10 \mathrm{~min}$ to obtain a packed mycelial volume (PMV) (\% w/v) and $\mathrm{pH}$ of the supernatant of the culture samples. Both data were plotted versus fermentation time (h) on a growth curve.

A $5 \mathrm{ml}$ aliquot of both cultures at optimum age was used medium. The culture was then shaken at $150 \mathrm{rpm}$ at $28{ }^{\circ} \mathrm{C}$. Samples were taken every $24 \mathrm{~h}$, after which all samples were centrifuged at $3571 \mathrm{xg}$ for $10 \mathrm{~min}$. The data of PMV (\% w/ v) and $\mathrm{pH}$ of the supernatant were plotted versus fermentation time $(\mathrm{h})$ on a biomass production curve.

The extraction, identification, and determination of monascidin A content in fermentation samples produced by M. purpureus parental strain and albino mutant were conducted employing the procedure of Blanc et al. (1995). Ten milliliters aliquots from each strain were extracted three times using methanol. The resultant extraction was filtered, washed two times with isooctane, and then an equal volume of water was added. The extract was acidified using sulfuric acid to give $\mathrm{pH}$ of 4.5 , then partitioned using methylene chloride. The bottom phase was dried, and then dissolved in methanol. A citrinin standard calibration curve was made at concentration levels of $0,5,10,15,20,25,30,35,40 \mu \mathrm{g} / \mathrm{ml}$ using commercial product (Sigma-Aldrich). Identification and determination of monascidin A content were carried out using HPLC (Hewlett-Packard) with a $214 \mathrm{~nm}$ UV detector. The mobile phase was methanol:water (1:1), with a $1.5 \mathrm{ml}$ $\mathrm{min}^{-1}$ flow rate in a C-18 Hypersil column at $40{ }^{\circ} \mathrm{C}$ column temperature.

\section{RESULTS}

Identification of Monascus sp. Identification of Monascus sp. employing RAPD using both primers CRL9 and CRL12 resulted in an RAPD band pattern that was identical to that of $M$. purpureus CECT2955T. This RAPD band pattern was different from the band pattern of $M$. ruber DSM1561. Therefore, it was concluded that Monascus sp. from Cikapundung River was M. purpureus. This was later named M. purpureus ITBCC-HD-F001 (Figure 1).

Mutant M. purpureus ITBCC-HD-F001. Mutation of M. purpureus ITBCC-HD-F001 using 3 and 4\% (v/v) EMS with a 60-min incubation time resulted in less than $10 \%$ mutant viability and unfortunately under those conditions white colonies could not be obtained from the albino mutant. Later, mutation was conducted using a lower EMS concentration and longer incubation time, i.e. EMS concentrations of 1.0, 1.5, 2.0, 2.5, 3.0\% (v/v) for $90 \mathrm{~min}$. Less than $10 \%$ mutant viability was obtained at an EMS concentrations of 2.5 and $3.0 \%(\mathrm{v} / \mathrm{v})$, but only the $2.5 \%(\mathrm{v} / \mathrm{v})$ EMS concentration could produce white colonies of $1.93 \times 10^{3}$ colonies $/ \mathrm{ml}$, with $6.01 \%$ mutant viability and $1.08 \%$ mutation efficiency. Color consistency and mutant stability tests showed that albino mutant colonies remained white on high-glucose medium (YMP-G) and YMP solid medium over five generations. This was consistent and the stable albino mutant was later named M. purpureus ITBCC-HD-F002.

Genetic Variation of M. purpureus ITBCC-HD-F002. The determination of genetic variation of $M$. purpureus ITBCC-HD-F002 using RAPD produced almost identical banding pattern compared to that of its parental strain, except for one additional band at $1150 \mathrm{bp}$ produced by primer CRL12. This band is the result from genetic change caused by EMS mutation in the albino mutant's DNA(Figure 2).

The Growth of M. purpureus ITBCC-HD-F001 and as inocula for the production process in $45 \mathrm{ml}$ YMP broth 


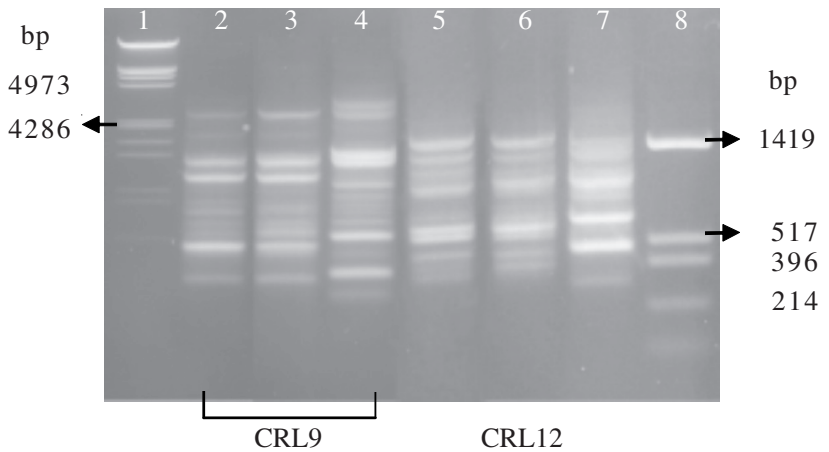

Figure 1 RAPD amplification results of Monascus sp. DNA using

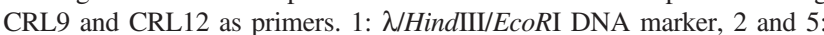
M. purpureus ITBCC-HD-F001, 3 and 6: M. purpureus CECT2955T, 4 and 7: M. ruber DSM1561, 8: pUC19/HinfI DNA marker.

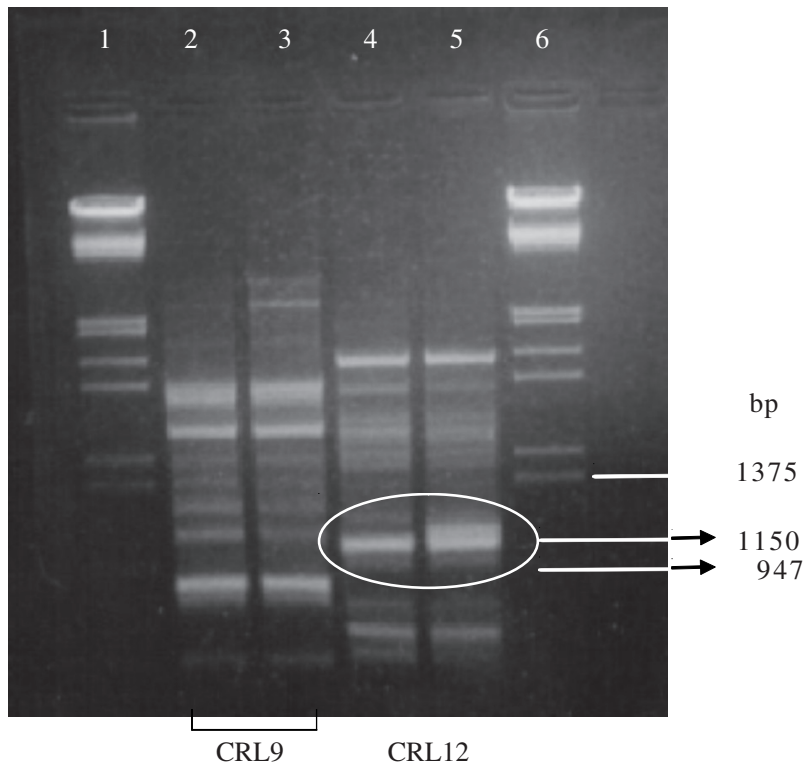

Figure 2 RAPD amplification results of the DNA of M. purpureus parental strain and albino mutant. 1 and 6: $\lambda /$ HindIII/EcoRI DNA marker, 2 and 4: parental strain (M. purpureus ITBCC-HD- F001), 3 and 5: albino mutant (M.purpureus ITBCC-HD- F002).

(Figure 3) showed that the growth rate of albino mutant (M. purpureus ITBCC-HD-F002) was slower than that of its parental strain (M. purpureus ITBCC-HD-F001). The growth curve peak shifted from $66^{\text {th }} \mathrm{h}$ in parental strain to $144^{\text {th }} \mathrm{h}$ in the albino mutant. The decrease of $\mathrm{pH}$ was faster in the parental strain fermentation compared to that of its mutant. The deceleration of growth rate also caused a change in the optimum age of inocula prepared for fermentation, from $64^{\text {th }}$ $\mathrm{h}$ in the parental strain to $102^{\text {nd }} \mathrm{h}$ in the albino mutant.

The two biomass production curves (Figure 4) showed that biomass production rate for albino mutant was slower than that of its parental strain, therefore production curve peak shifted from $72^{\text {nd }} \mathrm{h}$ with $12 \%$ (w/v) PMV (parental strain) to $120^{\text {th }} \mathrm{h}$ with $11.58 \%$ (w/v) PMV (albino mutant). It was also shown that medium $\mathrm{pH}$ fluctuated throughout both strains' fermentation processes.

Monascidin A. Identification employing HPLC revealed that both citrinin (monascidin A) standard and fermentation extracts from the parental strain and the albino mutant produced a chromatogram peak with average retention time of $1.7 \mathrm{~min}$. Therefore, it was concluded that monascidin A was found in the fermentation extracts of both strains. Two production curves of monascidin A (Figure 5), indicated that the monascidin A production rate by albino mutant was

$\frac{1}{3}$
0
0
0
$\vdots$
0
$\frac{\pi}{0}$
0
0
0
0
0
0
0
0

Figure 3 Growth curve of $M$. purpureus parental strain ( $\diamond \mathrm{PMV}, \square \mathrm{pH}$ ) and albino mutant. ( $\Delta \mathrm{PMV}, \mathrm{O} \mathrm{pH}$ )

Figure 4 Biomass production curve of $M$. purpureus parental strain ( $\diamond \mathrm{PMV}, \square \mathrm{pH}$ ) and albino mutant. ( $\Delta \mathrm{PMV}, \mathrm{O} \mathrm{pH}$ )
Figure 5 Monascidin A production curve of M. purpureus parental strain $(\diamond)$ and albino mutant $(\square)$. 
slower than that of its parental strain, resulted in the shifting of production curve peak from $96^{\text {th }} \mathrm{h}$ with $19.19 \mu \mathrm{g} \mathrm{ml}^{-1}$ monascidin A content (parental strain) to $144^{\text {th }} \mathrm{h}$ with $22.26 \mu \mathrm{g} \mathrm{ml}^{-1}$ monascidin A content (albino mutant).

\section{DISCUSSION}

Based on microscopic morphological characteristics on various growth media, Monascus sp. can be classified into M. pilosus, M. purpureus, and M. ruber (Hawksworth and Pitt 1983). It turns out that the identification of Monascus is very difficult to do if it is based only on microscopic morphology, so identification needs to be conducted using a molecular biology technique such as RAPD (Lakrod et al. 2000). Campoy et al. (2003) succeeded in characterizing Monascus sp. employing RAPD with 2 decamer (10-bases) primer, namely CRL9 and CRL12. The same procedure succeeded in identifying Monascus sp. isolated from Cikapundung River as M. purpureus, which was later named M. purpureus ITBCC-HD-F001.

An albino mutant was obtained through the mutation process of parental strain M.purpureus ITBCC-HD-F001 using $2.5 \%(\mathrm{v} / \mathrm{v})$ EMS with a 90 min incubation time. This mutant was produced when both mutant viability and mutation efficiency were below 10\%, as reported by Susilowati (1997) during the mutagenesis of Saccharomyces cerevisiae. Mutation under those conditions resulted in the substitution of base pairing in PKS gene for pigment biosynthesis.

Employing consistency and stability tests, albino mutant colonies were shown to be consistent and stable over five generations. Unstable albino mutants will turn red again on YMP-G medium because a high concentration of glucose can reverse the mutation. The consistent and stable albino mutant from this experiment was later named M. purpureus ITBCC-HD-F002.

Analysis of genetic variation caused by mutation was conducted employing RAPD. This analysis produced an additional $1150 \mathrm{bp}$ band. This band was the result of an amplification process by primer CRL12 on one DNA segment of the albino mutant chromosome, which was not present in parental strain DNA. This amplification happened because the an increased homology of this DNA segment to CRL12, which led to base pair substitution caused by EMS.

Characterization of the albino mutant through the comparisons of growth, biomass production, and monascidin
A production curves revealed that the growth, biomass production, and monascidin A production rates are slower compared with those of its parental strain. This indicated that EMS mutation decreased the ability of albino mutant to adapt to its growth surroundings. The increase of monascidin A production by the mutant at the peak of the production curve was caused by the accumulation of pigment precursor, which was also the precursor of monascidin A. All of the precursors were shifted to the monascidin A biosynthesis pathway, resulting in an increase of monascidin A production by the mutant.

\section{ACKNOWLEDGMENT}

This research was funded by Science and Technology Assessment and Research Project of the Indonesia Directorate General of Higher Education, Department of National Education, through Postgraduate Team Research Grant (HPTP) II, 2004-2006.

\section{REFERENCE}

Blanc PJ, Hajjaj H, Loret MO, Goma G. 1998a. Control of production of citrinin by Monascus. In: The Symposium on Monascus Culture and Applications. Toulouse-France: Laboratoire Biotechnologies-Bioprocedes INSA. 8-10 Jul 1998.

Blanc PJ, Loret MO, Goma G. 1995. Production of citrinin by various species of Monascus. Biotech Lett 17:291-294.

Blanc PJ, Loret MO, Goma G. 1998b. Pigments and citrinin production during cultures of Monascus in liquid and solid media. In: Advance in Solid State Fermentation. Toulouse-France: Laboratoire Biotechnologies-Bioprocedes INSA. p 393-406.

Campoy S, Perez F, Martin JF, Gutierrez S, Liras P. 2003. Stable transformants of Monascus purpureus obtained by protoplast transformation and Agrobacterium-mediated DNA transfer. Cur Genet 43:447-452.

Hajjaj $\mathrm{H}$ et al. 1999. Biosynthesis pathway of citrinin in the filamentous fungi Monascus ruber as revealed by ${ }^{13} \mathrm{C}$ Nuclear Magnetic Resonance. Appl Environ Microbiol 65:311-314.

Hawksworth DL, Pit JI. 1983. A new taxonomy of Monascus species based on the cultural and microscopical characters. Aus J Bot 31:51-61.

Lakrod K, Chaisrisook C, Yongsmith B, Skinner DZ. 2000. RAPD analysis of genetic variation within a collection of Monascus spp. isolated from red rice (angkak) and sofu. Mycol Res 104:403408.

Susilowati PE. 1997. Isolasi dan karakterisasi mutan resesif Sal4 di ragi Saccharomyces cerevisiae [Thesis]. Bandung: Institut Teknologi Bandung. 
